\title{
AÇÃO COMPORTAMENTAL RELACIONADA À ANSIEDADE E ASPECTOS ELETROFISIOLÓGICOS CEREBRAIS DA CAFEÍNA: ANÁLISE EM RATOS ALBINOS EM DESENVOLVIMENTO
}

\section{ACCIÓN DE COMPORTAMIENTO RELACIONADA CON LA ANSIEDAD Y LOS ASPECTOS ELECTROFISIOLÓGICOS CEREBRALES DE LA CAFEÍNA: ANÁLISIS EN EL DESARROLLO DE LAS RATAS ALBINAS}

\section{BEHAVIORAL ACTION RELATED TO ANXIETY AND BRAIN ELECTROPHYSIOLOGICAL ASPECTS OF CAFFEINE: ANALYSIS IN DEVELOPING ALBINE RATS}

\begin{abstract}
Maria Luísa Figueira de Oliveira ${ }^{1}$; Camila Lima Chagas ${ }^{2}$; Regina de Deus Lira Benevides ${ }^{3}$; Fernanda das Chagas Angelo Mendes Tenório ${ }^{4}$
\end{abstract}

DOI: https://doi.org/10.31692/978-65-991061-9-4.62-67

\section{INTRODUÇÃO}

A cafeína é uma das substâncias mais consumidas no mundo e está relacionada a várias funções fisiológicas, como, resistência física, alteração de humor e sono, atuando como um potente estimulador do Sistema Nervoso Central (SNC) (FREDHOLM et al., 1999). Em relação à sua ação sobre o SNC, a substância parece passar livremente do sangue para o cérebro, exercendo um efeito protetor dose-dependente, principalmente em doenças como Parkinson (CHEN, 2010). Com isso, prejuízos causados por essa substância durante o período de desenvolvimento podem acarretar déficits em longo prazo na função cerebral.

A cafeína é um psicoestimulante que parece agir através dos receptores da adenosina dos tipos A1 e A2 e dos receptores de dopamina do tipo D2. Seu consumo tem sido associado à melhora da cognição e desempenho de atletas, além do aumento do gasto energético e diminuição da ingestão energética. No entanto, quando consumida em doses altas (acima de $40 \mathrm{mg} / \mathrm{Kg}$ ) pode provocar insônia, irritabilidade e até mesmo ansiedade (FREDHOLM et al., 1999). Em ratos, observa-se que certas alterações comportamentais causadas pelo consumo de cafeína dependem da quantidade consumida (CHEN, 2010).

As propriedades da cafeína ocorrem devido à sua capacidade de interagir com neurotransmissores em diferentes regiões do encéfalo podendo, dessa forma, influenciar propriedades eletrofisiológicas no cérebro (POLESZAK et al., 2015). Evidencias apontam que a exposição à cafeína durante o desenvolvimento cerebral leva a um comprometimento da memória seletiva, que parece ser maior em ratas do que em ratos (CARROLL et al., 2004).

\footnotetext{
${ }^{1}$ Biomedicina, Universidade Federal de Pernambuco, malufigueira_2@outlook.com

${ }^{2}$ Curso, Instituição E-mail

${ }^{3}$ Curso, Instituição, E-mail

4 Titulação, Instituição, e-mail
} 
Dessa forma, objetiva-se investigar, em ratos albinos, a ação de diferentes doses de cafeína, aplicadas durante o desenvolvimento do sistema nervoso, no que se refere aos seus efeitos sobre o comportamento de ansiedade e peso corporal.

\section{FUNDAMENTAÇÃO TEÓRICA}

Estudos clínicos têm apontado para uma maior susceptibilidade de mulheres aos efeitos de outros psicoestimulantes (TEMPLE e ZIEGLER, 2011; ARDAIS et al., 2016). Além disso, alguns estudos demonstraram que o consumo agudo e crônico da cafeína em ratos adultos leva a alterações comportamentais sugestivas de ansiogênese.

$\mathrm{Na}$ literatura, foi analisado o efeito da administração da cafeína aguda no eixo hipotálamo-pituitária-adrenal (HPA). Embora não se tenha comprovação de um papel causal do HPA na ansiedade (ARMARIO et al, 2012), admite-se que ele pode contribuir de forma importante para a patogênese da depressão e ansiedade. (JEZOVA e HLAVACOVA, 2008;). Tanto em seres humanos, quanto em ratos, a cafeína aumenta expressivamente o hormônio adrenocorticotrófico (ACTH) (PATZ et al., 2006; O’NEILL, 2016).

Os efeitos da cafeína são comumente investigados em diversos sistemas fisiológicos, porém, no cérebro ainda não estão claramente definidos. (BLAHA et al., 2007). Diante disto, no presente estudo, ratos machos da linhagem Wistar foram submetidos, durante o período de desenvolvimento, a diferentes doses de cafeína através de gavagem e os efeitos desse tratamento sobre funções neurais foram então observados através de testes comportamentais e da Depressão Alastrante Cortical (DAC), uma resposta propagável, de despolarização celular com redução (depressão) da atividade elétrica do tecido cerebral cortical. (LEÃO, 1944). Essa resposta é consequência da estimulação de um ponto do tecido, sendo totalmente reversível. A estimulação, por sua vez, pode ser mecânica, química ou elétrica (LEÃO, 1944; GUEDES, 2005).

\section{METODOLOGIA}

O estudo foi realizado com ratos albinos Wistar machos. A cafeína foi administrada por gavagem, do $7^{\circ}$ ao $27^{\circ}$ dia de vida pós-natal, ( $n=15$ por grupo). Os grupos receberam solução contendo respectivamente 15, 30 ou $45 \mathrm{mg}$ de cafeína/Kg de peso corporal/dia (grupos Caf15, Caf30 e Caf45, respectivamente). Além desses, um grupo recebeu água destilada, isto é, o veículo usado para diluir a cafeína (grupo-V) e outro grupo não recebeu qualquer gavagem (grupo ingênuo-I). Os pesos corporais foram aferidos aos 7, 14, 21, 28 dias de vida. O teste de avaliação comportamental no labirinto em cruz elevado foi realizado aos 28 dias de vida e o 
teste do campo aberto aos 30 dias de vida. O trabalho foi aprovado pela Comissão de Ética (protocolo $\mathrm{n}^{\circ}$ 23076.034601/2015-22). Para as análises estatísticas utilizou-se a ANOVA, seguida, quando necessário, pelo teste de Holm-Sidak. Foram consideradas significativas as diferenças em que $\mathrm{p}<0,05$.

\section{RESULTADOS E DISCUSSÕES}

Aos 28 dias de vida os grupos Caf30 e Caf45 apresentaram pesos corporais menores (respectivamente $64,6 \pm 4,0 \mathrm{~g}$ e $58,9 \pm 3,8 \mathrm{~g}$ ) em comparação aos grupos ingênuo $(73,6 \pm 5,5 \mathrm{~g}$ ), veículo $(72 \pm 3,7 \mathrm{~g})$ e Caf15 $(70,5 \pm 4,5 \mathrm{~g})(\mathrm{p}<0,05)$ (Figura 1). Na análise do tempo por cada entrada, houve um aumento de forma dose-dependente nos animais tratados com cafeína no labirinto em cruz elevado e campo aberto, com valores significativamente maiores no grupo Caf45 em comparação ao grupo ingênuo. No teste do labirinto em cruz elevado o número do comportamento de levantar-se foi significativamente menor no grupo Caf45 em relação aos grupos controles, o número desse comportamento nos grupos ingênuo, veículo, CAF15, CAF30 e CAF45 foram respectivamente, $10,6 \pm 1,4,10,8 \pm 1,2,9,5 \pm 1,3,8,8 \pm 0,9,6,9 \pm 1,4$ ( $\mathrm{p}<0,05)$. No campo aberto o número de comportamento de levantar-se foi significativamente menor no grupo Caf45 em relação aos grupos controles e Caf15 (Figura 2). O número do comportamento de levantar-se dos grupos ingênuo, veículo, Caf15, Caf30 e Caf45 foram respectivamente, $9,5 \pm 1,4,9,8 \pm 1,4,7,5 \pm 1,2,6,6 \pm 1,4,4,8 \pm 0,9(\mathrm{p}<0,05)($ Gráfico 2).

Figura 1: Peso Corporal

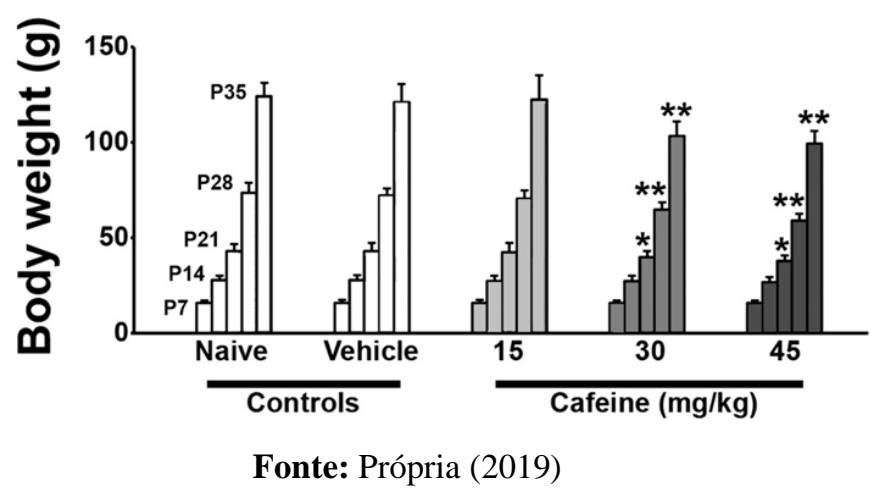

Figura 2: Labirinto em cruz elevada e campo aberto

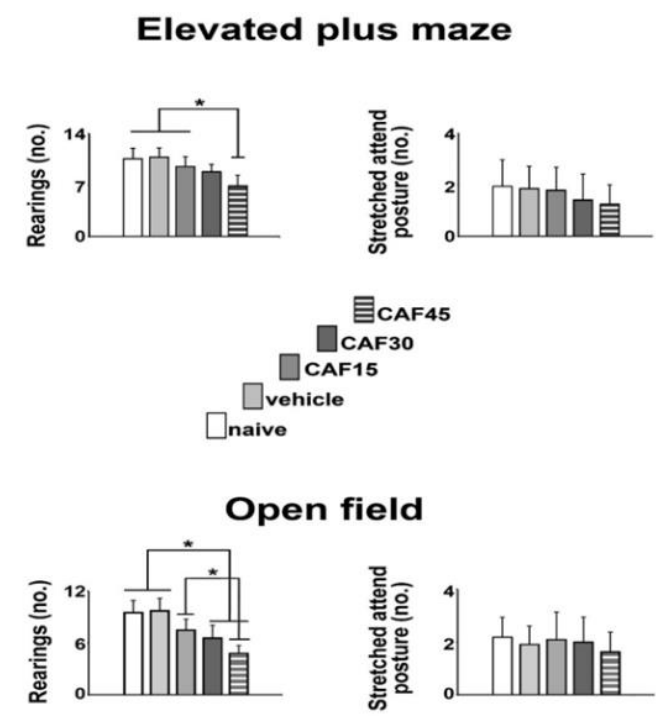

Fonte: Própria (2019) 
O tratamento sistêmico com cafeína reduziu o ganho de peso corporal dos animais, de forma proporcional às doses empregadas e aumentou a velocidade de propagação da DAC, enquanto que o tratamento tópico com cafeína, também alterou os parâmetros da DAC (aumentou velocidade de propagação e amplitude, e reduziu sua duração), refletindo um resultado novo para a ação eletrofisiológica da cafeína (Figuras 3 e 4).

Figura 3: Registro da DAC

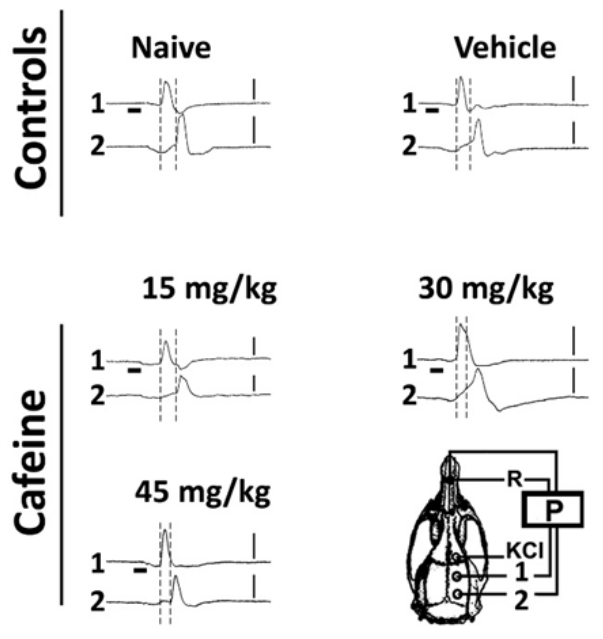

Fonte: Própria(2019)
Figura 4: Velocidade da DAC
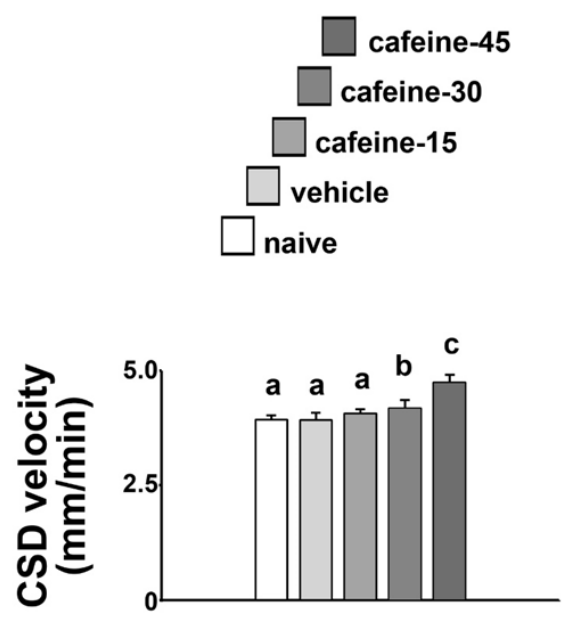

Fonte: Própria (2019)

Este estudo representa um achado pioneiro no que diz respeito à ação eletrofisiológica da cafeína, porém mais estudos são necessários para entender melhor a relação entre cafeína e excitabilidade cerebral. Nossos dados permitem que sugiramos cautela no consumo prolongado de cafeína por parte de gestantes, lactantes e crianças nos primeiros anos de vida, pois tal consumo pode levar a efeitos não desejáveis.

\section{CONCLUSÕES}

Esse estudo sugere que o tratamento com cafeína, em sua maior dose, durante o período de desenvolvimento cerebral causa redução do ganho do peso corporal e reduz o efeito de ansiedade. No entanto, extrapolar para seres humanos os dados encontrados nesse estudo é algo que requer cuidado, assim como a dose de cafeína consumida, visto que, em excesso, essa substância pode ter efeitos não desejáveis. As complexas interações entre cafeína, peso corporal e ansiedade necessitam de mais investigações.

Visando dar continuidade nesse trabalho, sugere-se como perspectivas:

- Investigar os efeitos do tratamento crônico com cafeína durante o período crítico de 
desenvolvimento sobre a memória (por meio de testes comportamentais específicos, como o labirinto aquático de Morris);

- Comparar os efeitos do tratamento com cafeína em diferentes períodos de desenvolvimento e gêneros;

- Analisar parâmetros bioquímicos dos animais tratados com cafeína em longo prazo;

- Comparar a ação do tratamento agudo e crônico da cafeína sobre efeitos eletrofisiológicos;

- Em modelos animais de consumo crônico de cafeína, estudar o impacto da sua abstinência sobre a depressão alastrante cortical;

- Investigar os efeitos da cafeína em condições muito favoráveis, ou desfavoráveis de lactação, representadas respectivamente pelo aleitamento em ninhadas com número reduzido, ou excessivo de filhotes.

\section{REFERÊNCIAS}

ARDAIS, A.P. et al. Caffeine triggers behavioral and neurochemical alterations in adolescent rats. Neuroscience, v. 270, p. 27-39, 2014.

ARMARIO, A. et al. What can we know from pituitary-adrenal hormones about the nature and consequences of exposure to emotional stressors?. Cellular Molecular Neurobiology, v. 32, p. 749-758, 2012.

BLAHA, M. et al. The effect of caffeine on dilated cerebral circulation and on diagnostic $\mathrm{CO} 2$ reactivity testing. Journal of Clinical Neuroscience, v. 14, p. 464-467, 2007.

CARROLL, M.E. et al. Sex and estrogen influence drug abuse. Trends Pharmacological Science, v. 25, p. 273-279, 2004.

CHEN, J. F. et al. What knock-out animals tell us about the effects of caffeine. Journal of Alzheimer's Dis-eases, v. 20, p. S17-S24, 2010.

FREDHOLM, B.B. et al. Actions of Caffeine in the Brain with Special Reference to Factors that Contribute to Its Widespread Use. Pharmacological Reviews, v. 51, p. 83-133, 1999.

GUEDES, R.C.A Electrophysiological Methods: Aplication in Nutritional neuroscience. In: Liebermann, H.; Kanarek, R.; Prasad, C. (eds), Nutritional Neurosciences: Overview of emerging field, p. 39-54, 2005.

JEZOVA, D.; HLAVACOVA, N. Endocrine factors in stress and psychiatric disorders: focus on anxiety and salivary steroids. Academic Science, v. 1148, p. 495-503, 2008.

LEÃO, A.A.P. Spreading depression of activity in the cerebral cortex. Journal of Neurophysiology, v. 7, p.359-390, 1944a. 
PATZ, M.D. et al. Modulation of the hypothalamo-pituitary-adrenocortical axis by caffeine. Psychoneuroendocrinology, v. 31, p. 493-500, 2006.

POLESZAK et al., 2015. The influence of caffeine on the activity of moclobemide, venlafaxine, bupropion and milnacipran in the forced swim test in mice. Life Science, v. 136, p. 13-18, 2015.

TEMPLE, J.L.; ZIEGLER, A.M. Gender differences in subjective and physiological responses to caffeine and the role of steroid hormones, Journal Caffeine Research, v. 1, p. 41-48, 2011. 